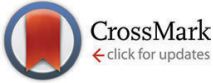

Cite this: Phys. Chem. Chem. Phys., 2015, 17, 17962

\title{
Emission spectroscopy of a ruthenium(II) polypyridyl complex adsorbed on calcium niobate lamellar solids and nanosheets $\dagger$
}

\begin{abstract}
Kazuhiko Maeda,* Takayoshi Oshima and Osamu Ishitani
$\mathrm{Ru}(\mathrm{II})$ tris-diimine complexes are known to exhibit emission at around $630 \mathrm{~nm}$ as a result of ${ }^{1} \mathrm{MLCT}$ photoexcitation. The emission is quenched in the presence of a suitable semiconductor solid due to electron injection from the excited state of a Ru(I) complex to the conduction band of the adjacent semiconductor. Here we investigated emission quenching behaviour of $\operatorname{Ru}^{\prime \prime}\left\{\left(4,4^{\prime}-\left(\mathrm{CH}_{3}\right)_{2}-\mathrm{bpy}\right)_{2}\left(4,4^{\prime}-\right.\right.$ $\left(\mathrm{CH}_{2} \mathrm{PO}_{3} \mathrm{H}_{2}\right)_{2}$-bpy)\} (bpy = 2,2' -bipryridine) adsorbed on $\mathrm{HCa}_{2} \mathrm{Nb}_{3} \mathrm{O}_{10}$ solids having an ordered lamellar structure or a disordered nanostructure. Even though electron injection from the excited state of the Ru complex to the conduction band of nanostructured $\mathrm{HCa}_{2} \mathrm{Nb}_{3} \mathrm{O}_{10}$ is thermodynamically less favorable than that of layered $\mathrm{HCa}_{2} \mathrm{Nb}_{3} \mathrm{O}_{10}$, faster electron injection was observed using nanostructured $\mathrm{HCa}_{2} \mathrm{Nb}_{3} \mathrm{O}_{10}$. Experimental results highlighted that electron injection from the excited $\mathrm{Ru}$ complex takes place not only in the conduction band of $\mathrm{HCa}_{2} \mathrm{Nb}_{3} \mathrm{O}_{10}$ but also mid-gap states whose density is strongly dependent on

both the morphological feature and the preparation method of $\mathrm{HCa}_{2} \mathrm{Nb}_{3} \mathrm{O}_{10}$.
\end{abstract}

Received 8th April 2015

Accepted 11th June 2015

DOI: $10.1039 /$ c5cp02050f

www.rsc.org/pccp

\section{Introduction}

Electron injection from the excited state of dyes or metal complexes into a semiconductor metal oxide is fundamentally important as the primary process of dye-sensitized solar cells and photocatalytic hydrogen evolution. ${ }^{1-13}$ Electron injection efficiency is known to depend on the conduction band potential $\left(E_{\mathrm{CB}}\right)$ of a metal oxide. For example, efficient electron injection from the excited state of $\mathrm{N} 3$ dye into $\mathrm{TiO}_{2}$ was observed, while that into $\mathrm{ZrO}_{2}$ having much more negative $E_{\mathrm{CB}}$ was very slow. ${ }^{4}$ Maitani et al. recently observed different charge injection behaviours of the excited state of anthracene dyes on $\mathrm{TiO}_{2}$ nanocrystals, which originated from different facets of $\mathrm{TiO}_{2}$ with different energies. $^{14}$

We have studied metal oxide nanosheets as building blocks for dye-sensitized $\mathrm{H}_{2}$ evolution in combination with ruthenium(II) polypyridyl complexes as redox photosensitizers. ${ }^{10-13}$ Ruthenium(II) tris-diimine complexes exhibit emission at around $630 \mathrm{~nm}$ as a result of ${ }^{1} \mathrm{MLCT}$ photoexcitation, and the efficiency of electron injection can be assessed by monitoring emission behaviour of the adsorbed Ru complex. ${ }^{11-13}$ According to our recent study on time-resolved emission spectroscopy, it was suggested that electron

Department of Chemistry, Graduate School of Science and Engineering, Tokyo Institute of Technology, 2-12-1-NE-2 Ookayama, Meguro-ku, Tokyo 152-8550, Japan. E-mail: maedak@chem.titech.ac.jp

$\dagger$ Electronic supplementary information (ESI) available: Additional spectroscopic and characterization data. See DOI: $10.1039 / \mathrm{c} 5 \mathrm{cp} 02050 \mathrm{f}$ injection from the excited state of $\mathrm{Ru}^{\mathrm{II}}\left\{\left(4,4^{\prime}-\left(\mathrm{CH}_{3}\right)_{2} \text {-bpy }\right)_{2}\left(4,4^{\prime}-\right.\right.$ $\left(\mathrm{CH}_{2} \mathrm{PO}_{3} \mathrm{H}_{2}\right)_{2}$-bpy $\left.)\right\}$, abbreviated as $\mathbf{R u}$ for simplicity, occurs not only in the conduction band of $\mathrm{HCa}_{2} \mathrm{Nb}_{3} \mathrm{O}_{10}$ nanosheets but also mid-gap states. ${ }^{14}$ If this is the case, the charge injection process should depend on the structural feature of $\mathrm{HCa}_{2} \mathrm{Nb}_{3} \mathrm{O}_{10}$. It is fundamentally interesting to investigate emission behaviour of a ruthenium(II) polypyridyl complex on a semiconductor solid having different morphological features. While there have been several reports on emission spectroscopy of metal-complex/ semiconductor hybrids focusing on different metal complexes and semiconductors, ${ }^{14-17}$ such structural effects of a metal oxide on the emission behaviour have not been investigated so far.

In this work, we investigated structural effects of $\mathrm{HCa}_{2} \mathrm{Nb}_{3} \mathrm{O}_{10}$ on the electron injection from the excited state of Ru by means of steady-state emission spectroscopy and time-resolved emission spectroscopy. Two types of $\mathrm{HCa}_{2} \mathrm{Nb}_{3} \mathrm{O}_{10}$ having distinct morphological features were synthesized: one is a submicron-order layered crystal and the other one is aggregated nanosheets with highly disordered structures, which was prepared by chemical exfoliation of the corresponding lamellar solid. In addition, we applied two different synthetic methods to prepare $\mathrm{HCa}_{2} \mathrm{Nb}_{3} \mathrm{O}_{10}$ having different physicochemical characteristics. The details of the materials preparation are included in the experimental section. Briefly, layered $\mathrm{HCa}_{2} \mathrm{Nb}_{3} \mathrm{O}_{10}$ was obtained by ion-exchange reaction of $\mathrm{KCa}_{2} \mathrm{Nb}_{3} \mathrm{O}_{10}$, which was prepared by a conventional solid-state reaction (SSR) or the polymerized complex (PC) method, with $\mathrm{HNO}_{3}$. Tetra( $n$-butyl)ammonium hydroxide (TBAOH), a bulky base molecule, was used to exfoliate layered $\mathrm{HCa}_{2} \mathrm{Nb}_{3} \mathrm{O}_{10}$ into 
unilamellar colloidal nanosheets. The $\mathrm{TBA}^{+}$-stabilized $\mathrm{Ca}_{2} \mathrm{Nb}_{3} \mathrm{O}_{10}{ }^{-}$ nanosheets were flocculated by adding $\mathrm{HCl}$, followed by washing with $\mathrm{H}_{2} \mathrm{O}$ and drying at $343 \mathrm{~K}$ overnight.

\section{Results and discussion}

Fig. 1A shows typical SEM images of layered $\mathrm{HCa}_{2} \mathrm{Nb}_{3} \mathrm{O}_{10}$ and the aggregated nanosheets prepared by the PC method. After exfoliation of lamellar $\mathrm{HCa}_{2} \mathrm{Nb}_{3} \mathrm{O}_{10}$ and subsequent restacking by $\mathrm{HCl}$, the original plate-like layered structure was completely destroyed, giving aggregated solids with a disordered structure. This result is also supported by XRD (Fig. 1B), which indicated that long-range ordering in the stacking direction (reflections from $(00 n)$ ) of the original layered material disappeared after the exfoliation-restacking process. Accompanied by this structural change, the specific surface area determined by nitrogen adsorption at $77 \mathrm{~K}$ was increased from 2.4 to $49 \mathrm{~m}^{2} \mathrm{~g}^{-1}$.

Fig. 1C shows UV-visible diffuse reflectance spectra of the same samples, along with an absorption spectrum of a Ru solution. Layered $\mathrm{HCa}_{2} \mathrm{Nb}_{3} \mathrm{O}_{10}$ shows a steep absorption edge at around $350 \mathrm{~nm}$, which is due to electron transition from the valence band formed by oxygen $2 p$ orbitals to the conduction band that consists of empty orbitals of niobium $4 \mathrm{~d}$. On the other hand, there are at least two absorption edges in the aggregated $\mathrm{HCa}_{2} \mathrm{Nb}_{3} \mathrm{O}_{10}$ nanosheets, both of which are blue-shifted compared to that in the parent layered solid. This is most likely due to a quantum-confinement effect. $^{18}$ As discussed in our previous paper, the generation of two absorption edges after the exfoliation-restacking process would result from an increase in the distortion of the two-dimensional nanosheet structure that consists of triple perovskite slabs having a
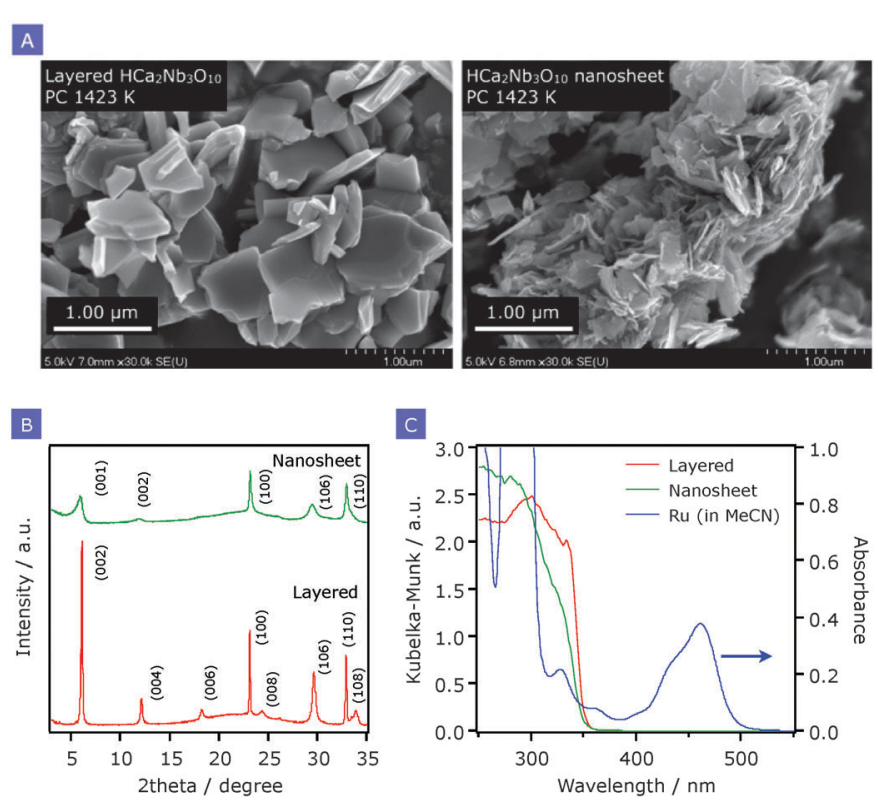

Fig. 1 (A) SEM images, (B) X-ray diffraction patterns, and (C) UV-visible diffuse reflectance spectra of layered $\mathrm{HCa}_{2} \mathrm{Nb}_{3} \mathrm{O}_{10}$ and $\mathrm{HCa}_{2} \mathrm{Nb}_{3} \mathrm{O}_{10}$ nanosheets prepared by the PC method calcined at $1423 \mathrm{~K}$. In panel (C), an absorption spectrum of $\mathbf{R u}(24 \mu \mathrm{M})$ in acetonitrile (MeCN) is shown for comparison. nanosized thickness. This more pronounced distortion might alter the local structure of $\mathrm{NbO}_{6}$ octahedra in the perovskite block, although the long-range ordering in the perovskite block (shown in XRD) appears to be maintained. Although the precise determination of the band-edge positions of the aggregated $\mathrm{HCa}_{2} \mathrm{Nb}_{3} \mathrm{O}_{10}$ nanosheets appears to be difficult, one may think that the valence band maximum and the conduction band minimum of $\mathrm{HCa}_{2} \mathrm{Nb}_{3} \mathrm{O}_{10}$ are shifted downward and upward, respectively, thereby leading to band-gap widening, as the result of nanostructuring. ${ }^{19}$

Using the two structurally different materials but with almost the same composition, the adsorption of Ru was performed by dispersing the solid materials in an aqueous solution containing Ru $\left(2.0 \mu \mathrm{mol} \mathrm{g}^{-1}\right)$. UV-visible spectroscopy showed that the dissolved Ru complex was quantitatively adsorbed on the surface of both materials. Note that, however, intercalation of $\mathbf{R u}$ into the gallery space of these solids does not occur, as revealed by our previous work. ${ }^{11,13}$ As shown in Fig. S1 (ESI $\dagger$ ), modification of $\mathrm{HCa}_{2} \mathrm{Nb}_{3} \mathrm{O}_{10}$ material with $\mathbf{R u}$ resulted in the generation of a new absorption band centred at around $460 \mathrm{~nm}$, which is due to MLCT transition of $\mathbf{R u}$, identical to $\mathbf{R u}$ in MeCN solution (Fig. 1C).

As reported previously, ${ }^{13} \mathbf{R u}$ on $\mathrm{Al}_{2} \mathrm{O}_{3}$ gives an emission peak at around $630 \mathrm{~nm}$ as a result of ${ }^{1} \mathrm{MLCT}$ photoexcitation of Ru at $444 \mathrm{~nm}$, with a quantum yield of $c a .5 .6 \%$ (Fig. 2). However, the emission was almost completely quenched when $\mathbf{R u}$ was loaded on $\mathrm{HCa}_{2} \mathrm{Nb}_{3} \mathrm{O}_{10}$ regardless of the structural feature. This indicates the occurrence of electron injection from the excited state of $\mathbf{R u}$ into $\mathrm{HCa}_{2} \mathrm{Nb}_{3} \mathrm{O}_{10}$. Note that these experiments assessed the electron injection process not only from the ${ }^{3}$ MLCT excited-state but also from ${ }^{1}$ MLCT, which is known to be an ultrafast process that occurs within a timescale of several hundreds of fs. ${ }^{2,3}$

The single-photon counting method was employed for measuring the decay of emission which was monitored at $630 \mathrm{~nm}$ after selective excitation of $\mathbf{R u}$ at $444 \mathrm{~nm}$. Fig. 3 shows decay curves of emission from $\mathbf{R u}$ adsorbed on layered $\mathrm{HCa}_{2} \mathrm{Nb}_{3} \mathrm{O}_{10}$ and the nanosheets prepared by the PC method. As a reference,

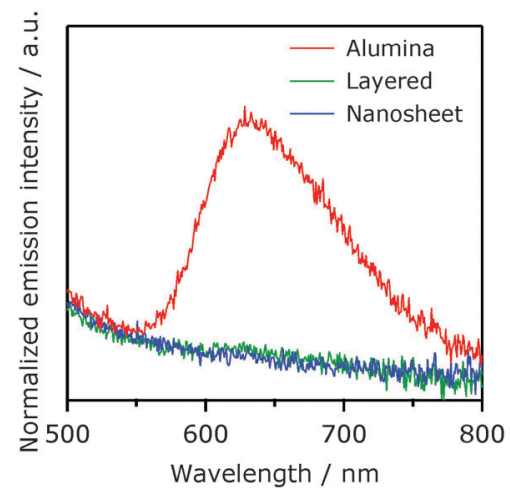

Fig. 2 Steady-state emission spectra of Ru on layered $\mathrm{HCa}_{2} \mathrm{Nb}_{3} \mathrm{O}_{10}$ and $\mathrm{HCa}_{2} \mathrm{Nb}_{3} \mathrm{O}_{10}$ nanosheets prepared by the PC method calcined at $1423 \mathrm{~K}$, along with that of $\mathbf{R u} / \mathrm{Al}_{2} \mathrm{O}_{3}$ for reference. The spectra were obtained by $444 \mathrm{~nm}$ photoexcitation. Note that reductive quenching of the ${ }^{3} \mathrm{MLCT}$ excited state of Ru by EDTA does not occur. 


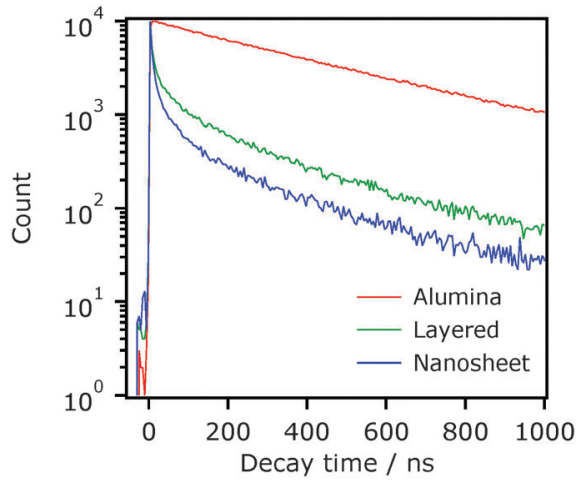

Fig. 3 Emission decay curves of $\mathbf{R u}$ on layered $\mathrm{HCa}_{2} \mathrm{Nb}_{3} \mathrm{O}_{10}$ and $\mathrm{HCa}_{2} \mathrm{Nb}_{3} \mathrm{O}_{10}$ nanosheets prepared by the $\mathrm{PC}$ method calcined at $1423 \mathrm{~K}$. Excited at $444 \mathrm{~nm}$ and monitored at $630 \mathrm{~nm}$, along with that of $\mathrm{Ru} / \mathrm{Al}_{2} \mathrm{O}_{3}$ for reference. For each sample, the measurement was repeated until the signal count just after photoexcitation (at $t=0$ ) reached $10^{4}$.

data on $\mathbf{R u} / \mathrm{Al}_{2} \mathrm{O}_{3}$ are also shown. Note that due to the time resolution of our apparatus ( $>200 \mathrm{ps}$ ), the observed emission decay is attributed to emission from the lowest ${ }^{3}$ MLCT excited state. ${ }^{20}$ Electron injection from the excited state of $\mathbf{R u}$ into $\mathrm{Al}_{2} \mathrm{O}_{3}$ does not proceed because of the insulating nature of $\mathrm{Al}_{2} \mathrm{O}_{3}$. It is clear that the emission decay of $\mathbf{R u}$ was more pronounced on the two $\mathrm{HCa}_{2} \mathrm{Nb}_{3} \mathrm{O}_{10}$ materials than on $\mathrm{Al}_{2} \mathrm{O}_{3}$, indicating the occurrence of electron injection from the excited state of $\mathbf{R u}$ into the $\mathrm{HCa}_{2} \mathrm{Nb}_{3} \mathrm{O}_{10}$ materials, consistent with the result of steady-state emission spectroscopy (Fig. 2). However, the emission decay of the layered material was relatively slow, whereas the nanosheet material showed a faster decay profile. It should be stressed that this tendency was independent of the preparation condition and method of $\mathrm{HCa}_{2} \mathrm{Nb}_{3} \mathrm{O}_{10}$; that is, a faster decay profile was observed in the nanosheet system (Fig. S2, ESI $\dagger$ ). The faster emission decay of the nanosheet material indicates the occurrence of faster electron injection. The faster electron injection of the nanosheet system compared to the layered one may seem unreasonable because one can expect an lowered driving force for electron injection due to the enlarged difference between the oxidation potential of the excited state $\left(E_{\mathrm{Ox}}{ }^{*}\right)$ and $E_{\mathrm{CB}}$ upon exfoliation-restacking. Therefore, there is another pathway of electron injection from the excited state of $\mathbf{R u}$ into $\mathrm{HCa}_{2} \mathrm{Nb}_{3} \mathrm{O}_{10}$. One plausible explanation is that part of electrons from the excited-state of $\mathbf{R u}$ are injected not only into the conduction band of the aggregated $\mathrm{HCa}_{2} \mathrm{Nb}_{3} \mathrm{O}_{10}$ nanosheets but also into mid-gap states in the material. ${ }^{2,3}$ It is known that in an n-type semiconductor including the present niobates, there are mid-gap states located below the conduction band. ${ }^{3}$ Here the highly disordered morphological feature of the aggregated $\mathrm{HCa}_{2} \mathrm{Nb}_{3} \mathrm{O}_{10}$ nanosheets could contain more defects that give localized states working as electron-accepting levels, compared to the ordered lamellar structured one. This situation would contribute to more efficient electron injection from the excited-state of $\mathbf{R u}$ into the aggregated $\mathrm{HCa}_{2} \mathrm{Nb}_{3} \mathrm{O}_{10}$ nanosheets.

We also tried to resolve the decay profiles of the same samples. However, it was very difficult especially for the nanosheet material even using four exponential functions, suggesting that Ru on the nanosheet material had different adsorption forms such as protonation/deprotonation of the phosphonate groups in the ligand.

If the idea (electron injection into mid-gap states) is correct, $\mathrm{HCa}_{2} \mathrm{Nb}_{3} \mathrm{O}_{10}$ having more structural imperfections will accelerate electron injection from the excited state of Ru more efficiently, resulting in a more pronounced emission decay profile. In order to investigate this, we prepared lamellar $\mathrm{HCa}_{2} \mathrm{Nb}_{3} \mathrm{O}_{10}$ and the aggregated nanosheets at lower calcination temperature (1023 K). By lowering calcination temperature in the final step of the PC method, one can prepare less-crystallized lamellar $\mathrm{HCa}_{2} \mathrm{Nb}_{3} \mathrm{O}_{10}$ and the nanosheet with smaller lateral dimensions, as revealed by our previous work. ${ }^{12}$ Here XRD patterns and SEM images of the as-prepared lamellar $\mathrm{HCa}_{2} \mathrm{Nb}_{3} \mathrm{O}_{10}$ solids are given in the ESI $\dagger$ (Fig. S3 and S4).

Fig. 4 compares the emission decay profiles of $\mathbf{R u}$ on two different $\mathrm{HCa}_{2} \mathrm{Nb}_{3} \mathrm{O}_{10}$ nanosheets prepared at 1023 and $1423 \mathrm{~K}$. As expected, lowering the calcination temperature of the PC method from 1423 to $1023 \mathrm{~K}$ accelerated the emission decay. This result further supports our claim that $\mathbf{R u}$ in the excited state injects an electron not only into the conduction band of $\mathrm{HCa}_{2} \mathrm{Nb}_{3} \mathrm{O}_{10}$ but also into mid-gap states.

The behaviour of emission decay of $\mathbf{R u}$ on the aggregated $\mathrm{HCa}_{2} \mathrm{Nb}_{3} \mathrm{O}_{10}$ nanosheets was further investigated with respect to the preparation method of the nanosheet. ${ }^{21}$ Fig. 4 also compares emission decays of $\mathbf{R u}$ adsorbed on two different $\mathrm{HCa}_{2} \mathrm{Nb}_{3} \mathrm{O}_{10}$ nanosheets, which were prepared by SSR and PC methods at the same calcination temperature (1423 K). Interestingly, a faster decay curve was observed in the sample prepared by the SSR method. This strongly suggests that the SSR-derived material contains more mid-gap states than the PC material. However, this may seem to contradict the results of structural characterization; i.e., the intensity of diffraction peaks of the SSR sample is much stronger than that of the PC sample, indicating that more pronounced crystallization occurred in the former (Fig. S3 and S4, ESI †). Nevertheless, it is known that the PC method allows one to obtain metal oxides with lower density of defects and/or vacancies even at lower temperatures, compared to a conventional SSR method. ${ }^{22,23}$ Accordingly, we believe that a slower emission decay profile recorded in the PC sample is reasonable.

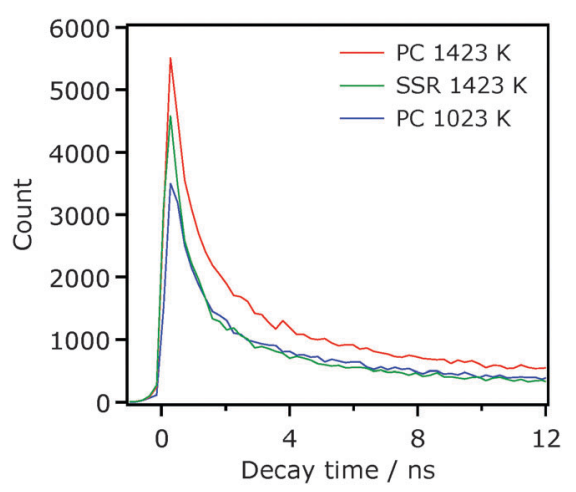

Fig. 4 Emission decay curves of $\mathrm{Ru}$ on $\mathrm{HCa}_{2} \mathrm{Nb}_{3} \mathrm{O}_{10}$ nanosheets prepared by different methods. Excited at $444 \mathrm{~nm}$ and monitored at $630 \mathrm{~nm}$, along with that of $\mathrm{Ru} / \mathrm{Al}_{2} \mathrm{O}_{3}$ for reference. Each measurement was conducted by irradiating the sample cell with a fixed number of photons. 


\section{Conclusions}

In summary, even though the conduction band potential of aggregated $\mathrm{HCa}_{2} \mathrm{Nb}_{3} \mathrm{O}_{10}$ nanosheets is slightly more negative than that of lamellar $\mathrm{HCa}_{2} \mathrm{Nb}_{3} \mathrm{O}_{10}$, electron injection from the excited state of $\mathbf{R u}$ is faster in the former than in the latter. Mid-gap states in the $\mathrm{HCa}_{2} \mathrm{Nb}_{3} \mathrm{O}_{10}$ nanosheets are suggested to accept electrons from the excited state of $\mathbf{R u}$, thereby facilitating the emission decay of Ru. Although it was believed that the $E_{\mathrm{CB}}$ of a semiconductor primarily determines the driving force for electron injection from the excited state of a redox photosensitizer, this is the first experimental result that strongly suggests significant contribution of mid-gap states existing in a semiconductor to the charge injection process. Mid-gap states that originate from defects and/or vacancies in a semiconductor solid are known to have a strong impact on photocatalytic activity of the semiconductor. ${ }^{24,25}$ Therefore, the present result may be useful as a probe to assess the density of defects and/or vacancies. Our research is now under way along this line.

\section{Experimental section}

\section{Preparation of layered $\mathrm{HCa}_{2} \mathrm{Nb}_{3} \mathrm{O}_{10}$}

First, $\mathrm{KCa}_{2} \mathrm{Nb}_{3} \mathrm{O}_{10}$ was synthesized by the polymerized complex method according to our previous papers. ${ }^{12,13}$ The final calcination temperature of the PC method varied from 1023 to $1423 \mathrm{~K}$ in order to control the size of lateral dimensions of $2 \mathrm{D}$ sheets. The detailed characterization data can be found in our previous paper. Then, the as-prepared $\mathrm{KCa}_{2} \mathrm{Nb}_{3} \mathrm{O}_{10}$ was subject to proton exchange with $1 \mathrm{M}$ $\mathrm{HNO}_{3}(100 \mathrm{~mL})$ for 6-7 days, followed by centrifugation to separate the resulting solid, which was washed with pure water until the $\mathrm{pH}$ of the supernatant became neutral.

$\mathrm{KCa}_{2} \mathrm{Nb}_{3} \mathrm{O}_{10}$ was also prepared by a solid-state reaction method according to a previous report. ${ }^{18} \mathrm{~K}_{2} \mathrm{CO}_{3}(\geq 99.5 \%$, Kanto Chemical Co.), $\mathrm{CaCO}_{3}$ ( $\geq 99.5 \%$, Kanto Chemical Co.), and $\mathrm{Nb}_{2} \mathrm{O}_{5}(\geq 99.95 \%$, Kanto Chemical Co.) were mixed with an agate mortar and pestle at a molar ratio of $\mathrm{K} / \mathrm{Ca} / \mathrm{Nb}=1.1 / 2 / 3$, and the mixture was calcined in air at $1123 \mathrm{~K}$ for $1 \mathrm{~h}$. An excess of $\mathrm{K}_{2} \mathrm{CO}_{3}(10 \mathrm{~mol} \%$ excess $\mathrm{K})$ was added to compensate for loss due to volatilization. After cooling to room temperature, the sample was mixed again, and was calcined in air at $1423 \mathrm{~K}$ for $10 \mathrm{~h}$. The as-prepared material was subject to proton-exchange in the same manner.

Elemental analysis by means of energy-dispersive X-ray spectroscopy (EDS) showed that approximately $95 \%$ of $\mathrm{K}^{+}$ions in the interlayer space were exchanged with protons. For simplicity, the obtained products will be referred to as $\mathrm{HCa}_{2} \mathrm{Nb}_{3} \mathrm{O}_{10}$.

\section{Preparation of aggregated $\mathrm{HCa}_{2} \mathrm{Nb}_{3} \mathrm{O}_{10}$ nanosheets}

Layered $\mathrm{HCa}_{2} \mathrm{Nb}_{3} \mathrm{O}_{10}$ samples were treated with an aqueous TBAOH solution to exfoliate the layered structure. The molar ratio of $\mathrm{TBA}^{+}$cations to exchangeable cations was 1 by mole. After shaking the suspension for 6-7 days, the resulting colloidal solution was allowed to stand for 1 day to precipitate the unreacted portion. After removal of the unreacted solids, the resulting nanosheet suspension was reassembled by adding $\mathrm{HCl}$, followed by washing with $\mathrm{H}_{2} \mathrm{O}$ in a similar manner.

\section{Adsorption of Ru complexes}

$\mathrm{Ru}\left\{\left(4,4^{\prime}-\left(\mathrm{CH}_{3}\right)_{2} \text {-bpy }\right)_{2}\left(4,4^{\prime}-\left(\mathrm{CH}_{2} \mathrm{PO}_{3} \mathrm{H}_{2}\right)_{2}\right.\right.$-bpy $\left.)\right\}\left(\mathrm{PF}_{6}\right)_{2}$ (bpy $=2,2^{\prime}-$ bipyridine), abbreviated as Ru in this work, was synthesized according to the previous literature with some modifications. ${ }^{26,27} \mathrm{It}$ was confirmed by ${ }^{1} \mathrm{H}-\mathrm{NMR}$ spectroscopy, electrospray ionizationmass spectroscopy (ESI-MS) and elemental analysis that the complexes were successfully synthesized.

The as-prepared $\mathrm{HCa}_{2} \mathrm{Nb}_{3} \mathrm{O}_{10}$ lamellar solid or aggregated nanosheet $(20 \mathrm{mg})$ was suspended in acetonitrile containing Ru (total volume, $10 \mathrm{~mL}$ ). After magnetically stirring overnight in the dark, the suspension was filtered, and the resulting paleorange powder was collected. Finally, the collected powder was dried in an oven at $343 \mathrm{~K}$ overnight. The amount of adsorbed Ru sensitizers onto a given substrate was estimated by using the following equation:

$$
\begin{aligned}
\text { Adsorbed amount }\left(\mu \mathrm{mol} \mathrm{g}{ }^{-1}\right)= & \frac{A_{\text {before }}-A_{\text {after }}}{A_{\text {before }}} \\
& \cdot \frac{\left.C(\mu \mathrm{mol} \mathrm{L})^{-1}\right) \times 10 \times 10^{-3}(\mathrm{~L})}{20 \times 10^{-3}(\mathrm{~g})}
\end{aligned}
$$

where $A_{\text {before }}$ and $A_{\text {after }}$ indicate the absorbance of Ru in a test solution at the ${ }^{3}$ MLCT maximum wavelength before and after the adsorption procedure, and $C$ is the concentration of the complex in the solution before adsorption, respectively.

\section{Steady-state emission spectroscopy}

Steady-state emission spectra were acquired using a multichannel spectrometer attached to a calibrated integrating sphere (C9920-02G, Hamamatsu Photonics) under $444 \mathrm{~nm}$ excitation at room temperature. The measurements were conducted by dispersing a $5.0 \mathrm{mg}$ of the powdered sample adsorbed with $\mathbf{R u}\left(2.0 \mu \mathrm{mol} \mathrm{g}^{-1}\right)$ in $3.0 \mathrm{~mL}$ of 10 mM EDTA aqueous solution under an Ar atmosphere.

\section{Time-resolved emission spectroscopy}

Emission decay monitored at $630 \mathrm{~nm}$, corresponding to the emission from $\mathbf{R u}$, was measured by the time-dependent single photon counting method using a FluoroCube 1000U-S spectrofluorometer under $444 \mathrm{~nm}$ photoexcitation (NanoLED-440L, HORIBA) with a TBX-04 detector at room temperature. A $5.0 \mathrm{mg}$ of $\mathbf{R u} / \mathrm{HCa}_{2} \mathrm{Nb}_{3} \mathrm{O}_{10}$ powder was dispersed in $3.0 \mathrm{~mL}$ of $10 \mathrm{mM}$ EDTA aqueous solution with continuous magnetic stirring under an Ar atmosphere.

\section{Acknowledgements}

This work was supported by the ENEOS Hydrogen Trust Fund, Grant-in-Aid for Scientific Research on Innovative Areas (Project No. 25107512; AnApple) and the PRESTO/JST program "Chemical Conversion of Light Energy". The authors would like to thank Prof. Takashi Hisatomi and Kazunari Domen (The University of Tokyo) for assistance in SEM observations and EDS measurements. K.M. acknowledges The Noguchi Institute for the financial support. 


\section{Notes and references}

1 A. Hagfeldt, G. Boschloo, L. Sun, L. Kloo and H. Pettersson, Chem. Rev., 2010, 110, 6595, and references therein.

2 R. Huber, S. Sebastian Spörlein, J. E. Moser, M. Grätzel and J. Wachtveitl, J. Phys. Chem. B, 2000, 104, 8995.

3 A. Furube, R. Katoh, K. Hara, S. Murata, H. Arakawa and M. Tachiya, J. Phys. Chem. B, 2003, 107, 4162.

4 R. Katoh, A. Furube, T. Yoshihara, K. Hara, G. Fujihashi, S. Takano, S. Murata, H. Arakawa and M. Tachiya, J. Phys. Chem. B, 2004, 108, 4818.

5 V. H. Houlding and M. Grätzel, J. Am. Chem. Soc., 1983, 105, 5695.

6 Y.-I. Kim, S. Salim, M. J. Huq and T. E. Mallouk, J. Am. Chem. Soc., 1991, 113, 9561.

7 E. Bae, W. Choi, J. Park, H. S. Shin, S. B. Kim and J. S. Lee, J. Phys. Chem. B, 2004, 108, 14093.

8 Q. Li, Z. Jin, Z. Peng, Y. Li, S. Li and G. Lu, J. Phys. Chem. C, 2007, 111, 8237.

9 R. Abe, K. Shinmei, K. Hara and B. Ohtani, Chem. Commun., 2009, 3577.

10 K. Maeda, M. Eguchi, W. J. Youngblood and T. E. Mallouk, Chem. Mater., 2008, 20, 6770.

11 K. Maeda, M. Eguchi, S.-H. A. Lee, W. J. Youngblood, H. Hata and T. E. Mallouk, J. Phys. Chem. C, 2009, 113, 7962.

12 K. Maeda, M. Eguchi, W. J. Youngblood and T. E. Mallouk, Chem. Mater., 2009, 21, 3611.

13 K. Maeda, G. Sahara, M. Eguchi and O. Ishitani, ACS Catal., 2015, 5, 1700.

14 M. M. Maitani, K. Tanaka, D. Mochizuki and Y. Wada, J. Phys. Chem. Lett., 2011, 2, 2655.

15 K. Hashimoto, M. Hiramoto, T. Sakata, H. Muraki, H. Takemura and M. Fujihira, J. Phys. Chem., 1987, 91, 6198.

16 W. E. Ford, J. M. Wessels and M. A. J. Rodgers, Langmuir, 1996, 12, 3449.

17 C.-W. Chang, C. K. Chou, I. Chang, Y.-P. Lee and E. W. Diau, J. Phys. Chem. C, 2007, 111, 13288.
18 T. Oshima, O. Ishitani and K. Maeda, Adv. Mater. Interfaces, 2014, 1, 1400131.

19 F. E. Osterloh, Chem. Soc. Rev., 2013, 42, 2294.

20 T. Yui, H. Takeda, Y. Ueda, K. Sekizawa, K. Koike, S. Inagaki and O. Ishitani, ACS Appl. Mater. Interfaces, 2014, 6, 1992.

21 Here, the integration of the signal count profile from $t=0$ (just after photoexcitation) to $t=\infty$ corresponds, in principle, to the emission quantum yield. Therefore, time-resolved emission measurement should be done in this way. Due to different morphological characteristics of different materials, however, the $y$-axis count depends on the material employed. To avoid this complication, we normalized data obtained using different materials by repeating the measurement until the signal count reached 10000 (Fig. 3). Nevertheless, we should be able to apply this way (irradiation with a fixed number of photons) when we compare materials with similar structural features. That is why we used different representations in the $y$ axis shown in Fig. 4 . Actually, the nanosheet materials shown in Fig. 4 have rough surface structures with almost the same surface area (approximately $\left.50 \mathrm{~m}^{2} \mathrm{~g}^{-1}\right)$. We wish to point out that the direct measurement of emission strength cannot be employed for determining the emission quantum yield because light scattering by the nanosheet should cause disunity of the number of photons absorbed by the Ru complex.

22 M. Kakihana, J. Sol-Gel Sci. Technol., 1996, 5, 7.

23 S. Ikeda, M. Hara, J. N. Kondo and K. Domen, Chem. Mater., 1998, 10, 72.

24 S. Ikeda, N. Sugiyama, S.-y. Murakami, H. Kominami, Y. Kera, H. Noguchi, K. Uosaki, T. Torimoto and B. Ohtani, Phys. Chem. Chem. Phys., 2003, 5, 778.

25 K. Maeda, N. Murakami and T. Ohno, J. Phys. Chem. C, 2014, 118, 9093.

26 B. Gholamkhass, H. Mametsuka, K. Koike, M. Furue and O. Ishitani, Inorg. Chem., 2005, 44, 2326.

27 M. R. Norris, J. J. Concepcion, C. R. K. Glasson, Z. Fang, A. M. Lapides, D. L. Ashford, J. L. Templeton and T. J. Meyer, Inorg. Chem., 2013, 52, 12492. 